\title{
Association Between Delayed Diagnosis Of Breast Cancer And Its Degree Of Invasiveness Among The Patients In Tertiary Care Hospital Of Karachi
}

\author{
Suha Zubairi, Hassan Mirza, Aisha Qamar
}

\section{ABSTRACT}

Objective: To find the association between delayed diagnosis of breast cancer over the degree of invasiveness for each of the immune-histochmically defined molecular type of invasive ductal carcinoma among the patient in tertiary care hospital of Karachi.

Study Design and Setting: A cross sectional study was conducted on 153 post mastectomy patients in a time frame of two years at Bait-ul-Sukoon Hospital who had their immunohistochemistry workup.

Methodology: The patients included in the research were diagnosed cases of breast cancer; had post-mastectomy with their histopathological and immunochemistry status work up reports. In addition to demographic variables; the histopathological report of specimen, histological tumor type and grade, invasive tumor size, axillary lymph node status, Paget's disease and stage of the disease were recorded from the histopathological report however ER, PR and Her 2 neu receptor statuses were confirmed via immunochemistry report. Volume of the tumor was calculated using the following formula $\mathrm{V}=\left(\mathrm{W}^{2} \times \mathrm{L}\right) / 2$ Convenient sampling was applied and the data was analyzed on SPSS 20.0 with CI-95\% and P=0.05.

Results- All 153 patients reported because of unpleasant symptoms.47.1\% of the participants presented with LT while the remaining $52.9 \%$ were grouped as NLT. The association of molecular type with stage at mastectomy was statistically significant $(\mathrm{P}=0.015)$ in the ERG. Her-2 enriched variant shows that there was a moderate positive statistically significant relationship between log of total delay and log of tumor volume +2 .

Conclusion: Delay in diagnosis due to lack of screening modalities, lesser awareness among low socioeconomic groups and inaccessibility to tertiary care were not the major causes of aggressive tumors at diagnosis in developing countries, instead all the major known risk factors influence to the tumor burden collectively .

Keywords: Breast Carcinoma, Delayed diagnosis, Immunohistochemistry, Invasiveness, Post mastectomy.

\section{INTRODUCTION:}

Breast carcinoma is one of the most prevalent forms of neoplastic tissue growth amounting for $23 \%$ of diagnosed carcinoma and $14 \%$ of deaths among women of all ages and ethnicities across the world. ${ }^{1}$ As per to the data available, 1.7 million cases were reported in the year 2012 with a $35.5 \%$ rise in mortality rate from $2000-2011 .^{2,3}$ In the recent years breast carcinoma is proving to be the commonest female malignancy in the developing Asian countries, despite the prevalence being lower in Asian region than compared to the Western developed countries, the mortality rate are disproportionately higher. ${ }^{4,5,6}$ According to latest statistical reports carried out in 2015, Pakistan is emerging as Asia's hub with 2.5 time higher incidence, 1 in 9 women during their life time develop breast carcinoma. ${ }^{7,8}$

Suha Zubairi
Final Year MBBS
Bahria University Medical and Dental College
Email: suha.zubairi@yahoo.com
Hassan Mirza
Final Year MBBS
Bahria University Medical and Dental College
Aisha Qamar
Professor, Anatomy Department
Rahria University Medical and Dental College
Received: 15-10-2019

A significant contributing factor to the breast cancer deaths globally is delay in the diagnosis, which comprises of two parts; patient delay and medical system delay. ${ }^{910}$ The delay itself is multifactorial which is observed due to lack of female awareness regarding the presentation of the disease, poverty, poor access to health care facility, widespread illiteracy, cultural stigma, lack of resources to offer screening programs and limited amount of human expertise. ${ }^{11,12,13,14}$

Staging of breast carcinoma is a process to find out the invasiveness and spread of the cancer within the normal tissue. According to American Joint Committee on Cancer (AJCC) the TNM system is implemented to stage breast cancer, ${ }^{15,16}$ which comprises of

1- T- primary tumor size,

2- N- lymph node involvement

3- M- Distant metastasis.

Specific combination of TNM invasion is grouped into 4 classes from I-IV. With I being the least invasive form and the IV the most highly invaded form. ${ }^{16,17}$ Highly invasive form confirmed by trucut biopsy at the time of diagnosis; and has the worst prognostic characteristics resulting in higher mortality rates for this disease. ${ }^{18}$

All the different histological and molecular classes of invasive adenocarcinoma shows unique growth pattern, proliferative rates, nodal involvement, distant metastasis and long term prognosis rate. ${ }^{19,20}$ This raises the great dilemma that whether 
the diagnostic delay irrespective of the tumor's intrinsic makeup is the chief factor responsible for the advanced degree of invasive component of the tumor or presence of specific rapid proliferative morphological and molecular subtype is a must for highly invasive tumor masses. The effect of delay in diagnosis over the prognosis of the disease is controversial and cannot be studied in randomized controlled trails due to ethical regulations. Hence this study was designed as a retrospective study and was the rationale of study. This study was aimed to find the association between delayed diagnoses of breast cancer over the degree of invasiveness for each of the immune-histochemically defined molecular types of invasive ductal carcinoma.

\section{METHODOLOGY:}

This was a cross sectional study conducted at Bait ulSukun Hospital, Karachi, in a time frame of two years from July 2017 to July 2019. The patients included in the research were diagnosed cases of breast cancer; who had undergone mastectomy with their histopathological and immunochemistry status work up report. The subjects in the study were included after informed consent with no other added interventions except data collection keeping in mind the inclusion and exclusion criteria. The study was approved by the ethical review committee of Bahria University Medical and Dental College, Karachi. The demographics variables include age, ethnicity, education status, contact number, family history of breast cancer, and the ability to re-call the dates as to when the symptoms appeared, when the subjects presented to the clinic and when was a diagnosis made were documented in the questionnaire. Patients with neo adjuvant chemo or radiotherapy were not included in the study. From September' 17 to September' 18 ; total 320 women with diagnosed cases of breast carcinoma at Bait Us Sukoon Hospital were selected; from which 153 questionnaires were fully validated through initial hospital medical file survey supplemented with a phone call mediated structured questionnaire-based interview. In addition to demographic variables; histological tumor type and grade, invasive tumor size, axillary lymph node status, Paget's disease and stage of the disease were recorded from the histopathological report however ER, PR and Her 2 neu receptor statuses were confirmed via immunochemistry report.

Tumors were grouped according to their grading and immunohistochemistry microarray analysis; they were graded on the basis of glandular/tubular differentiation and nuclear pleomorphism, grade 1 being well differentiated whereas grade 3 being poorly differentiated. While, luminal molecular variant consisted of tumors labelled ER +ve, PR +ve /-ve, Her $2+v e /-v e$ whereas non luminal variant consisted of basal (triple negative) variant with ER -ve, PR -ve and Her 2 -ve and Her 2 enriched variant with ER -ve, PR -ve and Her $2+$ ve statuses.

Tumor with luminal molecular variant were grouped as luminal group while those with Her-2 enriched and basal molecular type were grouped together under the non-luminal category. Patients who took less than a year from recognition of symptoms to presenting in clinic and acquiring definitive surgical treatment were grouped as early report group (ERG) while those who took more than a year for the entire process were grouped as late report group (LRG).

Delay in the diagnosis, comprises of patient delay and medical system delay. Patient delay is the time span between the appearances of the first symptom/s to the first consultation with a medic whereas; the medical system delay being the time from first consultation to an exact diagnosis to the initiation of treatment. SPSS version 23 was used for data analysis and p-value $<0.05$ was considered statistically significaent. Chi square was carried out to asses association of stage at mastectomy to the molecular variant and total delay. Volume of the tumor was calculated using the following formula $\mathrm{V}=\left(\mathrm{W}^{2} \times \mathrm{L}\right) / 2$. In order to satisfy the rule of normality $\log$ (total delay) and log (Tumor volume +2 ) was also calculated. The assumption of normality was tested using Shapiro-Wilk test for normality and skewness. Pearson correlation analysis was carried out separately for all the three molecular variants to find out if there is any significant correlation between the two variables.

\section{RESULTS:}

Data concerning the demographic characteristics of the patients included in the study group and the tumor features are summarized in table 1 . The participants included were in the age group of 26 to 70 years, with $45.8 \%$ being in the age band of 41 to 55 years. Almost a two third of sample size i.e. $74.4 \%$ were pre-menopausal. The laterality of the specimen was almost equal in the study as $47.1 \%$ of the patients had their right breast affected while the rest of $52.9 \%$ had the left breast involved. None of the subjects had any history of recurrent carcinomas.

Among the symptoms for which these women initially consulted a breast clinic, lump or a swelling in the breast was the most common as $90.2 \%$ sought consultation as a result of it. Among $87.6 \%$ of the subject the delay from recognition of symptoms to acquiring definitive surgical treatment was less than a year hence they were categorized as the early report group (ERG). $47.1 \%$ of the participants presented with luminal molecular pattern while the remaining $52.9 \%$ were grouped as Non-luminal molecular variant (HER-2 enriched and basal). Only 3.9\% had stage I disease while the remaining $41.2 \%$ and $54.9 \%$ had stage II and III respectively. Similarly, only $1.3 \%$ presented with grade I tumor while the remaining $39.2 \%$ and $59.5 \%$ were grade II and III tumors respectively.

Table 2- shows crosstab to asses association between the stage of the mastectomy specimen with the molecular variant of the tumor, luminal and non-luminal $(\mathrm{P}=0.089)$ and also with time delay until definitive surgical treatment, early report group and late report group $(\mathrm{P}=0.357)$. Furthermore, 
Suha Zubairi, Hassan Mirza, Aisha Qamar

Table -1 Demographic characteristics of patients and tumor feature

\begin{tabular}{|c|c|c|c|c|}
\hline Parameter & Categories & $\begin{array}{c}\text { Luminal } \\
\text { (Non-Aggressive tumor } \\
\text { type) }\end{array}$ & $\begin{array}{c}\text { Non-Luminal } \\
\text { (Aggressive tumor type) } \\
\text { (Her-2 enriched and basal) }\end{array}$ & Total \\
\hline Total frequency & & 72 & 81 & 153 \\
\hline Age & $\begin{array}{l}26-40 \\
41-55 \\
55-70\end{array}$ & $\begin{array}{l}20 \\
32 \\
20\end{array}$ & $\begin{array}{l}30 \\
38 \\
13\end{array}$ & $\begin{array}{l}50 \\
70 \\
33\end{array}$ \\
\hline Ethnicity & $\begin{array}{c}\text { Urdu Speaking } \\
\text { Punjabi } \\
\text { Sindhi } \\
\text { Balochi } \\
\text { Pakhtoon } \\
\end{array}$ & $\begin{array}{c}54 \\
9 \\
2 \\
3 \\
4 \\
\end{array}$ & $\begin{array}{l}62 \\
6 \\
3 \\
8 \\
2 \\
\end{array}$ & $\begin{array}{c}116 \\
15 \\
5 \\
11 \\
6 \\
\end{array}$ \\
\hline $\begin{array}{l}\text { Educational } \\
\text { Status }\end{array}$ & $\begin{array}{l}\text { Lower to intermediate } \\
\text { Higher to Intermediate }\end{array}$ & $\begin{array}{l}61 \\
11\end{array}$ & $\begin{array}{l}61 \\
20\end{array}$ & $\begin{array}{c}122 \\
31\end{array}$ \\
\hline $\begin{array}{l}\text { Family History } \\
\text { of Breast Cancer }\end{array}$ & $\begin{array}{l}\text { Yes } \\
\text { No }\end{array}$ & $\begin{array}{l}15 \\
57\end{array}$ & $\begin{array}{l}19 \\
62\end{array}$ & $\begin{array}{c}34 \\
119\end{array}$ \\
\hline $\begin{array}{l}\text { Specimen } \\
\text { Laterality }\end{array}$ & $\begin{array}{l}\text { Right } \\
\text { Left }\end{array}$ & $\begin{array}{l}31 \\
41\end{array}$ & $\begin{array}{l}40 \\
40\end{array}$ & $\begin{array}{l}71 \\
81\end{array}$ \\
\hline $\begin{array}{l}\text { Histological } \\
\text { Tumor Variant }\end{array}$ & $\begin{array}{c}\text { Invasive Ductal Carcinoma } \\
\text { Others }\end{array}$ & $\begin{array}{l}59 \\
13 \\
\end{array}$ & $\begin{array}{l}71 \\
10 \\
\end{array}$ & $\begin{array}{l}130 \\
23\end{array}$ \\
\hline Stage & $\begin{array}{l}\text { I } \\
\text { II } \\
\text { III }\end{array}$ & $\begin{array}{c}3 \\
23 \\
46 \\
\end{array}$ & $\begin{array}{c}3 \\
40 \\
38 \\
\end{array}$ & $\begin{array}{c}6 \\
63 \\
84 \\
\end{array}$ \\
\hline Grade & $\begin{array}{c}\text { I } \\
\text { II } \\
\text { III } \\
\end{array}$ & $\begin{array}{c}2 \\
34 \\
36 \\
\end{array}$ & $\begin{array}{c}0 \\
26 \\
55 \\
\end{array}$ & $\begin{array}{c}2 \\
60 \\
91 \\
\end{array}$ \\
\hline Paget's Disease & $\begin{array}{l}\text { Yes } \\
\text { No }\end{array}$ & $\begin{array}{l}16 \\
56 \\
\end{array}$ & $\begin{array}{l}13 \\
68 \\
\end{array}$ & $\begin{array}{c}29 \\
124\end{array}$ \\
\hline $\begin{array}{l}\text { Delay in } \\
\text { Reporting }\end{array}$ & $\begin{array}{l}\text { Within one Year } \\
\text { More than one year }\end{array}$ & $\begin{array}{c}64 \\
8\end{array}$ & $\begin{array}{l}70 \\
11\end{array}$ & $\begin{array}{c}134 \\
19\end{array}$ \\
\hline
\end{tabular}

Table-2 Association between stage at diagnosis with molecular variant versus reporting delay

\begin{tabular}{|c|c|c|c|c|c|c|}
\hline & & Stage I & Stage II & Stage III & Total & P-values \\
\hline \multirow{3}{*}{ Molecular variant } & Luminal & 3 & 23 & 46 & 72 & \multirow{3}{*}{0.089} \\
\hline & Non-Luminal & 3 & 40 & 38 & 81 & \\
\hline & Total & 6 & 63 & 84 & 153 & \\
\hline \multirow{3}{*}{ Reporting Delay } & Within one Year & 6 & 57 & 71 & 134 & \multirow{3}{*}{0.357} \\
\hline & More than one year & 0 & 6 & 13 & 19 & \\
\hline & Total & 6 & 63 & 84 & 153 & \\
\hline
\end{tabular}

Table-3 Association of stage at diagnosis with molecular subtype in early versus late report group

\begin{tabular}{|l|l|c|c|c|c|c|}
\hline \multicolumn{2}{|c|}{} & Stage I & Stage II & Stage III & Total & P-values \\
\hline \multirow{3}{*}{$\begin{array}{l}\text { Within one year } \\
\text { (ERG) }\end{array}$} & Luminal & 3 & 19 & 42 & 64 & \multirow{3}{*}{0.015} \\
\cline { 2 - 7 } & Non-Luminal & 3 & 38 & 29 & 70 & \multirow{3}{*}{0.141} \\
\cline { 2 - 7 } & Total & 6 & 57 & 71 & 134 & \\
\hline \multirow{2}{*}{$\begin{array}{l}\text { More than one } \\
\text { year (LRG) }\end{array}$} & Within one Year & 0 & 4 & 4 & 8 & \multirow{2}{*}{19} \\
\cline { 2 - 6 } & More than one year & 0 & 2 & 9 & 11 & \\
\cline { 2 - 6 } & Total & 0 & 6 & 13 & 19 & \\
\hline
\end{tabular}

Table-4 Pearson correlation between (Log of tumor volume +2 ) and (Log of Total delay)

\begin{tabular}{|l|l|c|l|}
\hline \multicolumn{2}{|l|}{ Log of Tumor Volume +2} & Log of Total delay & P-value \\
\hline Luminal & 0.035 & 0.385 \\
\hline \multirow{2}{*}{ Non-Luminal } & Her-2 enriched & 0.271 & 0.036 \\
\cline { 2 - 4 } & Basal & 0.211 & 0.108 \\
\hline
\end{tabular}


a subgroup analysis of ERG versus LRG in order to assess any association of stage at mastectomy with luminal and non-luminal variant is shown in table-3. The association of molecular type with stage at mastectomy was statistically significant $(\mathrm{P}=0.015)$ in the ERG while it was not significant among the participants in the LRG $(\mathrm{P}=0.141)$

Table- 4 shows the results of Pearson correlation to assess statistically significant correlation between Log of tumor volume +2 and $\log$ of Total delay for each molecular variant separately. The result for Her-2 enriched variant shows that there was a moderate positive statistically significant relationship between $\log$ of total delay $(\mathrm{M}=2.06, \mathrm{SD}=0.41)$ and $\log$ of tumor volume +2 (Her-2 enriched variant) $(\mathrm{M}=1.48, \mathrm{SD}=0.58)(\mathrm{r}(43)=0.271, \mathrm{p}<0.05)$, one-tailed. This relationship can account for $7.34 \%$ of variation of scores $\left(\mathrm{R}^{2}=0.0734\right)$.

\section{DISCUSSION:}

Mammography is one of the screening modality that aids in identifying asymptomatic breast cancers, according to studies done in 2017-18, it was established that it has its advantage of reducing breast cancer mortality rate by $40 \%$ along with its limitation of having low sensitivity and specificity with increasing number of false positive results. ${ }^{21}$

However, in our study all 153 patients reported because of unpleasant symptoms instead of a prophylactic mammographic screening. Thus, due to lack of screening modalities in a developing country like Pakistan, It was hypothesized that delay in diagnosis substantially results in an advance stage of the disease. .

Early diagnosis and effective prompt treatment have been the core principles of oncology department, coherent with this a previous study conducted in Dalarna County, Sweden ${ }^{22}$ has suggested that patients with shorter delay have less aggressive disease and better prognosis with $60 \%$ lower risk of dying from breast cancer within 10 years after diagnosis and $47 \%$ lower risk of dying from breast cancer within 20 years after diagnosis ${ }^{25}$. Consistent with our figures where $47 \%$ of patients in ERG presented with stage I/II disease while $0 \%$ and $31.6 \%$ of the LRG presented at stage I and stage II respectively, yet not statistically significant $(\mathrm{P}=0.357)$.

Similarly, the LT and NLT molecular variants and their stage at diagnosis did not reach statistical significance $(\mathrm{P}=0.089)$, but the fact that both these factors i.e. delay in diagnosis and molecular variant adds to the tumor burden cannot be undermined as a whole because within the ERG the stage distribution among the LT and NLT was statistically significant $(\mathrm{P}=0.015)$ where $\mathrm{LRG}$ showed no obvious stage distribution within the other 2 molecular variants. Furthermore, only the tumor volume of Her-2 enriched variant in the NLT group showed statistical significance $(\mathrm{P}=0.036)$ with mildly positive correlation (Pearson $=0.271$ ) against the total delay, meanwhile the tumor volume of other molecular variants had no obvious trend against the total delay. This as a whole strengthens our point of view that when these individual factors are analyzed as a group, a definitive pattern can be highlighted that influences tumor burden in comparison to when viewed separately.

A number of different factors including age at diagnosis, tumor volume, lymph node infiltration, distant metastases, molecular subtype and grade at presentation have been used collaboratively to group patients into various risk categories such as the NIH consensus criteria ${ }^{22}$, the Nottingham prognostic index ${ }^{23}$ and the St Gallen criteria ${ }^{24}$. Breast carcinoma being a multi-factorial disease assessing the above factors in combination to one another is of greater clinical value than viewing them in isolation. On the contrary, implementation of these risk categories have shown better value when assessing prognosis in group of patients rather than individual patient with breast cancer in daily clinical practice, hence newer more advanced modalities such as molecular techniques including gene expression profiling consisting of hormone receptors ER, PR, Her-2, antibodies to CK5/6, Epidermal growth factor receptor, Ki67 expression have been used to quantify prognosis on individual basis.

Since breast cancer within the family enhances the chances of impacting the first degree relatives which was also supported in our study with $22.2 \%$ of the subjects having a positive family history of the disease hence we can look into BRCA gene as one of the screening modality which can help in detecting disease at a much earlier stage.

Our study had a few limitations, which include small sample size from a single breast cancer set up in Karachi, patients who had neo-adjuvant chemotherapy were disregarded in the study, any patient with a delay of more than two years was excluded due to human error in recalling dates and stage IV disease with metastasis was excluded hence it could be said that our results cannot be generalized to the entire population.

It is recommended that future researches should be conducted on a large scale that would cover more than one breast cancer set up, the studies should also correlate other immunologic markers such as Ki-67, CD44, CD24, BRCA, EGFR and ALDH1 to the prognosis of breast cancer and lastly, the studies should evaluate the response of hormonal therapy given post mastectomy in luminal and non-luminal types of breast cancers that can help in tailoring the drug regimens.

\section{CONCLUSION:}

Delay in diagnosis due to lack of screening modalities, lesser awareness among low socioeconomic groups and inaccessibility to tertiary care were not the major causes of aggressive tumors at diagnosis in developing countries, instead all the major known risk factors influence to the tumor burden collectively which includes molecular subtypes, grade at presentation and histological tumor variant. 


\section{REFERENCES:}

1- JemalA, Bray F, Center MM, Ferlay J, Ward E, Forman D. Global cancer statistics. CA Cancer JClin. 2011; 61(2): 69-90.

2- Youlden DR, Cramb SM, Yip CH, Baade PD. Incidence and mortality of female breast cancer in the Asia-Pacific region. Cancer Biol Med. 2014;11(2):101-15.

3- Ferlay J, Soerjomataram I, Ervik M, Dikshit R, Eser S, Mathers C, et al. GLOBOCAN 2012 v1.0, Cancer Incidence and Mortality Worldwide: IARC CancerBase No. 11;

4- Agarwal G, Pradeep PV, Aggarwal V, Yip CH, Cheung PS. Spectrum of breast cancer in Asian women. World J Surg. 2007;31(5):1031-40.

5- Shibuya K, Mathers CD, Boschi PC, Lopez AD, Murray CJ. Global and regional estimates of cancer mortality and incidence by site. II. Results for the global burden of disease 2000 . BMC Cancer. 2002;2:37.

6- Begum N. Breast Cancer in Pakistan: A Looming Epidemic. J Coll Physicians Surg Pak. 2018;28(2):87-8.

7- Sohail S, Alam SN. Breast cancer in Pakistan-awareness and early detection. J Coll PhysiciansSurg Pak. 2007; 17(12):7112.

8- Zaheer S, Shah N, Maqbool SA, Soomro NM. Estimates of past and future time trends in age-specific breast cancer incidence among women in Karachi, Pakistan: 2004-2005. BMC Public Health. 2019;19:1001.

9- Caplan L. Delay in Breast Cancer: Implication for Stage at Diagnosis and Survival. Front Public Health. 2014;2:87.

10- Sharma K, Costas A, Shulman LN, Meara JG. A systematic review of barriers to breast cancer care in developing countries resulting in delayed patient presentation. J Oncol. 2012:8.

11- Khan MA, Shafique S, Khan MT, Shahzad MF, Iqbal S. Presentation delay in breast cancer patients, identifying the barriers in North Pakistan. Asian Pac J Cancer Prev. 2015; 16(1): 377-80.

12- Akhtar M, Akulwar V, Gandhi D, Chandak K. Is locally advanced breast cancer a neglected disease? Indian J Cancer. 2011; 48(4): 403-5.

13- Igene H. Global health inequalities and breast cancer: an impending public health problem for developing countries. Breast J. 2008; 14(5):428-34.
14- Khan TM, Leong JPY, Ming LC, Khan AH. Association of knowledge and cultural perception of Malaysian women with delay in diagnosis and treatment of breast cancer: a systematic review. Asian Pac J Cancer Prev. 2015; 16(13):5349-57.

15- Koh J, Kim MJ. Introduction of a New Staging System of Breast Cancer for Radiologists: An Emphasis on the Prognostic Stage. Korean J Radiol. 2019; 20(1):69-82.

16- American Cancer Society. Breast Cancer Stages [Internet]. Georgia, USA: American Cancer Society; 2019 [updated 2019 September; cited 2019 July 10]. Available from: https://www. cancer.org/cancer/breast-cancer/understanding-a-breast-cancerdiagnosis/stages-of-breast-cancer.html

17- Breast Cancer.org. Breast Cancer Stage [Internet]. Pennsylvania USA: Breast Cancer.org; 2019 [updated 2019 July 23; cited 2019 Aug 5]. Available from: https://www.breastcancer .org/symptoms/diagnosis/staging

18- Bradley CJ, Given CW, Roberts C. Disparities in cancer diagnosis and survival. Cancer. 2001;91(1):178-88.

19- Cianfrocca M, Gradishar W. New molecular classifications of breast cancer. CA Cancer J Clin. 2009;59(5):303-13.

20- Yersal O, Barutca S. Biological subtypes of breast cancer: Prognostic and therapeutic implications.World J ClinOncol. 2014;5(3):412-24

21- Wang L. Early Diagnosis of Breast Cancer. Sensors (Basel). 2017;17(7):1572.

22- Tabar L, Dean PB, Chen TH, Yen AM, Chen SL, Fann JC, et al. The incidence of fatal breast cancer measures the increased effectiveness of therapy in women participating in mammography screening. Cancer. 2018; 125(4): [preceding p.1].

23- Eifel P, Axelson JA, Costa J, Crowley J, Curran WJ, Deshler A, et al. National Institutes of Health Consensus Development Conference Statement: adjuvant therapy for breast cancer, November 1-3, 2000. J Natl Cancer Inst. 2001; 93(13): 979-89.

24- Galea MH, Blamey RW, Elston CE, Ellis IO. The Nottingham Prognostic Index in primary breast cancer. Breast Cancer Res Treat. 1992; 22(3):207-19.

25- Goldhirsch A, Ingle JN, Gelber RD, Coates AS, Thurlimann B, Senn HJ, et al. Thresholds for therapies: highlights of the St Gallen International Expert Consensus on the primary therapy of early breast cancer 2009. Ann Oncol. 2009; 20(8): 1319-29. 